\title{
Comparison of Common Adverse Neonatal Outcomes Among Preterm and Term Infants at the National Referral Hospital in Tanzania: A Case- Control Study
}

Bernadether Terentius Rugumisa ( $\nabla$ kokurugumisa@gmail.com )

University of Dar es Salaam

Raphael Zozimus Sangeda

Muhimbili University of Health and Allied Sciences

Erik Bongcam-Rudloff

Swedish University of Agricultural Sciences

Sylvester Leonard Lyantagaye

University of Dar es Salaam

Siriel Nanzia Massawe

Muhimbili University of Health and Allied Sciences

\section{Research Article}

Keywords: neonatal outcomes, infants, prematurity, Tanzania

Posted Date: June 25th, 2021

DOI: https://doi.org/10.21203/rs.3.rs-613224/v1

License: (c) (i) This work is licensed under a Creative Commons Attribution 4.0 International License.

Read Full License 


\section{Abstract}

\section{Background}

The first month of life is the most critical in a child's heath because it is associated with the highest risk of adverse health outcomes. In Tanzania the risk of adverse health outcomes in preterm infants is five times higher compared to term infants. The objective of this study was to assess common adverse health outcomes and compare the risk of such outcomes between preterm and term infants, in Tanzania, within the first 28 days of life.

\section{Methods}

This was a case-control study involving preterm (cases) and term (controls) infants delivered at the Muhimbili National Hospital between August and October 2019 . About 222 pairs of cases and controls were reviewed for their medical records. Logistic regression was used to compare the risk of neonatal outcomes between the study groups. Statistical significance was achieved at $P$-value $<0.05$ and $95 \%$ confidence interval.

\section{Results}

Preterm infants have an increased risk of mortality $(\mathrm{OR}=7.2,95 \% \mathrm{Cl}$ : $3.4-15.1)$, apnea $(\mathrm{OR}=4.7,95 \% \mathrm{Cl}$ : 3.4-15.1), respiratory distress syndrome $(\mathrm{OR}=4.8,95 \% \mathrm{Cl}: 3.2-7.3)$, necrotizing enterocolitis $(\mathrm{OR}=5.5$, $95 \% \mathrm{Cl}: 1.2-25.3)$, anemia ( $\mathrm{OR}=4.3,95 \% \mathrm{Cl}: 2.8-6.6)$, pneumonia ( $\mathrm{OR}=2.7,95 \% \mathrm{Cl}: 1.6-4.6)$ and sepsis $(\mathrm{OR}=2.6,95 \% \mathrm{Cl}: 1.7-3.9)$ in the first month of life compared to term infants. No differences in the risk of intraventricular hemorrhage, bronchopulmonary dysplasia, patent ductus arteriosus and jaundice were observed between preterm and term infants.

\section{Conclusion}

The findings of this study informs the Tanzanian health sector about the most common and high risk neonatal outcomes in preterm infants. Additionaly, for promoting neonates' health, the health sector needs to consider preventing and treating the most common and high risk adverse neonatal outcomes in preterm infants.

\section{Background}

The neonatal period is the most critical time in a child's life. The neonatal period is a time of major and rapid anatomical and physiological changes required for a newborn's adaptation to extra-uterine life. The changes may also be accompanied by adverse outcomes resulting from failure to adapt or due to a definite high risk of infections quickly. Such outcomes put neonates at the highest risk of mortality and morbidity than infants of higher age groups ${ }^{1,2}$. 
Neonatal mortality is responsible for approximately $50 \%$ of all deaths in children under five years ${ }^{3}$. Around two-thirds of these deaths occur in only ten countries, all low or middle-income countries ${ }^{4}$. The predominant causes of adverse neonatal outcomes are preterm birth, infections, intrapartum-related complications and congenital anomalies. According to the World Health Organization (WHO) and the Maternal and Child Epidemiology Estimation group, it was estimated that in 2017 preterm birth. Intrapartum-related complications and infections accounted for $35 \%, 24 \%, 14 \%$ and $73 \%$, respectively, of the neonatal deaths worldwide ${ }^{5}$.

With an estimated 45,000 neonatal deaths annually and a mortality rate of 32 per 1000 live births, Tanzania ranks number ten among countries with the greatest number of neonatal deaths ${ }^{6}$. Preterm birth accounts for $35 \%$ of the neonatal deaths in Tanzania ${ }^{7}$. Nearly one out of two preterm infants experience adverse health outcomes during the neonatal period, making the risk of morbidity five times higher compared to term infants ${ }^{8,9}$. Although most neonatal health problems are preventable, there are no clear guidelines for assessing neonates' health and care for preterm infants in most Tanzania health care facilities, resulting from a gap of knowledge about appropriate points of intervention ${ }^{10}$.

This study aimed to assess common adverse health outcomes and compare the risk of such outcomes between preterm (born at less than 37 weeks gestation) and term infants (born at greater than or at 37 weeks gestation) within the first 28 days of life.

\section{Materials And Methods}

\section{Study Site}

This research was conducted at the Muhimbili National Hospital $(\mathrm{MNH})$ neonatal ward. $\mathrm{MNH}$ is located in Dar es Salaam-Tanzania $\left(6.8034^{\circ} \mathrm{S}, 39.2738^{\circ}\right)$ on a natural harbor on East Africa's eastern coast. MNH is a national referral and a teaching hospital for medical students, nurses and postgraduates from the Muhimbili University of Health and Allied Sciences (MUHAS). It is also the only National Hospital in Tanzania that attends inpatients, outpatients and referral cases from all over the country. At the hospital, newborns are admitted in the maternity block with their mothers and may be moved to the neonatal unit if they develop health complications.

\section{Study Design}

This hospital-based case control study was conducted on newly born infants within the first month of life between August and October 2019. All new deliveries were monitored daily between August and October 2019 and infants were defined as preterm or term. Preterm infants were born at less than 37 weeks of gestation and were regarded as cases. Term infants were born at greater than or equal to 37 weeks of gestation and were regarded as controls. Controls were obtained through the identification of a term infant born immediately after a preterm infant was enrolled.

\section{Sample Size Determination}


The sample size was calculated using EPI info (7.1.3.10) matched pair formula for case-control studies. The minimum sample size at $95 \%$ confidence interval $(\mathrm{Cl}), 80 \%$ power and $15 \%$ prevalence of preterm birth was 106 pairs. In this study, the sample size was slightly increased for higher accuracy of results.

\section{Inclusion and Exclusion Criteria}

All newborns delivered at $\mathrm{MNH}$ were eligible for the study. Only live singleton newborns delivered within the study period were included in the study. A live newborn was defined by presenting a cry, breathing or movement after delivery and Apgar score of less than one at one and five minutes. Newborns whose parents did not sign a consent form were excluded from the study. Newborns with congenital anomalies were also excluded from the study.

\section{Data Collection}

Birth details that included an infant's identification, gestational age, sex, Apgar score, birth weight and admission ward were recorded immediately after birth. Many pre-identified expected adverse neonatal outcomes were assessed by reviewing the neonate's medical files using a pre-structured chart. Data was collected from the time of birth to discharge or death.

\section{Statistical Analysis}

Data were prepared and analyzed using Statistical Package for the Social Sciences (SPSS) version 20 (IBM Corp., Armonk, NY, USA) for Windows version 20. Descriptive statistics were used to summarize outcomes as means and proportions. T-test was used to determine the statistical significance of means. For proportions, the fisher's exact test was used. Logistic regression was used to compare the risk of neonatal outcomes between the study groups. A $P$-value of less than 0.05 at $95 \% \mathrm{Cl}$ was considered statistically significant.

\section{Results}

A total of 222 case-control pairs were recruited in this study. Six (2.2\%) preterm infants and 16 (7.2\%) preterm infants, respectively, were excluded from the analysis due to congenital malformations or unsigned parent consent forms. Of the remaining 206 preterm infants, $9(4.4 \%)$ were extreme preterm (less than 28 weeks gestation), 63 (30.6\%) were very preterm (28-31 weeks gestation) and 134 (65.0\%) were moderate to late preterm (32-36 weeks gestation).

Baseline neonatal characteristics are presented in Table 1. There were more males than females in both case and control groups, although the proportion of male to female was not statistically significantly different. Mean birth weight was $2.0 \pm 0.7 \mathrm{~kg}$ for preterm infants and $3.1 \pm 0.6 \mathrm{~kg}$ for term infants. There was a statistically significant difference in the mean birth weight ( $p$-value $<0.001)$. The proportion of preterm infants who weighed less than $2500 \mathrm{~g}$ was significantly higher when compared to term infants $(p$-value $<0.001)$. There was no significant difference for less than or equal to the five Apgar score at one and five minutes between the two groups. 
Table 1

Baseline characteristics of preterm and term infants at Muhimbili National Hospital

\begin{tabular}{|c|c|c|c|}
\hline \multirow[t]{2}{*}{ Characteristics } & \multicolumn{2}{|l|}{$\mathbf{N}(\%)$} & \multirow[t]{2}{*}{$p$-value } \\
\hline & Preterm $(n=206)$ & Term $(n=217)$ & \\
\hline \multicolumn{4}{|l|}{ SEX } \\
\hline Male & $110(53.4)$ & $132(60.8)$ & 0.140 \\
\hline Female & $96(46.6)$ & $85(39.2)$ & \\
\hline \multicolumn{4}{|c|}{ BIRTH WEIGHT (grams) } \\
\hline$\geq 2500$ & $47(22.8)$ & 192(88.5) & $<0.001$ \\
\hline$<2500$ & 159(77.2) & $25(11.5)$ & \\
\hline \multicolumn{4}{|c|}{ APGAR SCORE $\leq 5$} \\
\hline At 1 minute & $31(15.0)$ & $22(10.1)$ & 0.29 \\
\hline At 5 minute & $8(3.9)$ & $2(0.9)$ & \\
\hline
\end{tabular}

On average, the duration of hospital stay was longer among preterm infants than term infants, and the difference was statistically significant ( $p$-value $<0.05)$. Apnea, respiratory distress syndrome (RDS), necrotizing enterocolitis (NEC), pneumonia, anemia and sepsis were significantly common among preterm than term infants (Table 2). No significant differences were observed between the two groups for intraventricular hemorrhage (IVH), bronchopulmonary dysplasia (BPD), patent ductus arteriosus (PDA) and jaundice ( $p$-value $=0.06,1.00,0.11$ and 0.20 , respectively). 
Table 2

Health complications among preterm and term infants

\begin{tabular}{|llllll|}
\hline Complications & \multicolumn{2}{l}{ Preterm $(\mathbf{N}=\mathbf{2 0 6})$} & \multicolumn{2}{l}{ Term $(\mathbf{N}=217)$} & p-value \\
\cline { 2 - 5 } & $\mathbf{N}$ & $\%$ & $\mathbf{N}$ & $\%$ & \\
\hline Death & 49 & 23.8 & 9 & 4.2 & $<0.001$ \\
\hline Apnea & 149 & 72.3 & 78 & 35.9 & $<0.001$ \\
\hline IVH & 4 & 1.9 & 0 & 0.0 & 0.055 \\
\hline RDS & 155 & 75.2 & 84 & 38.7 & $<0.001$ \\
\hline BPD & 1 & 0.5 & 2 & 0.9 & 1.000 \\
\hline PDA & 3 & 1.5 & 0 & 0.0 & 0.115 \\
\hline NEC & 10 & 4.9 & 2 & 0.9 & 0.018 \\
\hline Jaundice & 119 & 57.8 & 111 & 53.9 & 0.200 \\
\hline Anemia & 106 & 51.5 & 43 & 19.8 & $<0.001$ \\
\hline Pneumonia & 52 & 25.2 & 24 & 11.1 & $<0.001$ \\
\hline Sepsis & 105 & 51.0 & 62 & 28.6 & $<0.001$ \\
\hline $\begin{array}{l}\text { Abbreviations: IVH, intraventricular hemorrhage; RDS, respiratory distress syndrome; BPD, } \\
\text { bronchopulmonary dysplasia; PDA, patent ductus arteriosus; NEC, necrotizing enterocolitis }\end{array}$ \\
\hline
\end{tabular}

Generally, 175/206 (85.0\%) preterm infants and 94/217 (43.3\%) term infants had at least one adverse outcome and the difference was statistically significant ( $p$-value $<0.001)$. The proportion of infants with at least one outcome increased with lower gestational ages (Fig. 1). All infants born at less than 28 weeks had at least one adverse outcome. Also, $93.7 \%$ and $79.9 \%$ of those born between $28-31$ weeks and 32-36 weeks, respectively, had at least adverse outcomes. However, the majority of those born at greater than or equal 37 weeks had no adverse outcome.

Furthermore, preterm infants were a significantly higher mortality rate than term infants during the neonatal period ( $p$-value $<0.001)$. There were more deaths in lower gestational ages than in higher gestational ages. Forty-nine out of $206(23.8 \%)$ preterm infants and nine out of $217(4.1 \%)$ term infants died within the neonatal period (Table 2). The number of deaths to the number of births increased substantially with decreasing gestational age group (Fig. 2). While only 9/217 infants born at greater than or equal to 37 weeks died, all (9/9) infants born at less than 28 weeks died. For gestational ages of 28-31 weeks and 32-36 weeks, 21/63 and 19/134 infants died, respectively.

Table 3 shows the likelihood of the significant adverse outcomes to occur among preterm and term infants. The risk of apnea, RDS and NEC were more or less than five times higher among preterm infants. Preterm infants were four times likely to have anemia than term infants. Similarly, infections like sepsis and pneumonia were nearly three times more common among preterm than term infants. Of all adverse 
neonatal outcomes studied, death had the most odds of occurrence. In comparison to term infants, the risk of death was seven-fold higher in preterm infants. The risk of overall morbidity was also higher in preterm infants than term infants by seven-folds.

Table 3

The odds of health complications among preterm and term infants.

\begin{tabular}{|c|c|c|c|c|}
\hline Outcome & $\begin{array}{l}\text { Preterm infants } \\
\mathrm{n}=\mathbf{2 0 6}\end{array}$ & $\begin{array}{l}\text { Term infants } \\
\mathrm{n}=\mathbf{2 1 7}\end{array}$ & OR & $95 \% \mathrm{Cl}$ \\
\hline Mortality $\ddagger$ & 49 & 9 & 7.2 & $3.4-15.1$ \\
\hline Apneał & 149 & 78 & 4.7 & $3.1-7.0$ \\
\hline RDS $\ddagger$ & 155 & 84 & 4.8 & $3.2-7.3$ \\
\hline NEC* & 10 & 2 & 5.5 & $1.2-25.3$ \\
\hline Anemiał & 106 & 43 & 4.3 & $2.8-6.6$ \\
\hline Pneumonia† & 52 & 24 & 2.7 & $1.6-4.6$ \\
\hline Sepsisł & 105 & 62 & 2.6 & $1.7-3.9$ \\
\hline Overall morbidity $\ddagger$ & 175 & 94 & 7.4 & $4.6-11.8$ \\
\hline \multicolumn{5}{|c|}{$\begin{array}{l}\text { Abbreviations: OR; odds ratio, Cl; confidence interval, RDS; respiratory distress syndrome, NEC; } \\
\text { necrotizing enterocolitis }\end{array}$} \\
\hline
\end{tabular}

\section{Discussion}

This study assessed adverse neonatal outcomes and compared the risk between preterm and term infants. The findings indicate that nearly a quarter $(23.8 \%)$ of preterm infants and only $4.1 \%$ of term infants died during the neonatal period. A similar mortality rate of $28 \%$ for preterm and $6 \%$ for term infants was reported in a study conducted in Bangladesh ${ }^{11}$. Contrary, a lower mortality rate among preterm infants was reported in high-income countries like Australia (7.7\%) and the USA $(1.4 \%){ }^{12,13}$. These differences show that preterm infants in low and low-middle-income countries are at a greater risk of mortality than those in high-income countries. Mortality risk was seven times higher $(\mathrm{OR}=7.2,95 \% \mathrm{Cl}$; 3.4-15.1) in preterm infants than term infants. Previous studies have also reported a five to 12 increased risk of mortality in preterm infants $9,14,15$.

Number of deaths to live births significantly increased with decreasing gestational age and led to as high as $100 \%$ mortality rate among extreme preterm infants. A very high mortality rate among extreme preterm infants is not surprising. In a similar situation in England, a survival rate of only $2 \%$ (98\% mortality rate) in 
extreme preterm infants was reported ${ }^{16}$. For moderate and late preterm infants, more than one-third and one-seventh of the infants died, respectively. A higher mortality rate among moderate (54\%) than late preterm infants (13.2\%) was also reported in a prospective study for causes of death and illnesses in preterm infants in Ethiopia ${ }^{17}$.

The current study observed that, on average, preterm infants had a longer duration of hospitalization than term infants (eleven vs. four days). A comparable duration of ten days for preterm and five days for term infants was reported in a previous study comparing short-term neonatal morbidity between preterm and term infants ${ }^{18}$. However, a national-wide survey reported a considerably longer duration of hospitalization for preterm infants that ranged between three to 74 days depending on the degree of prematurity of an infant ${ }^{13}$. Fewer days of hospitalization in the present study may be due to early deaths among preterm infants. Also, in this study, there were only a few extreme preterm infants, that are usually the ones staying longer at the hospital ${ }^{13}$.

The present study shows that the proportion of preterm infants with neonatal morbidity was nearly twice that of term infants (84.9\% vs. 43.3\%). In a study conducted in Bangladesh, similar proportions were observed, whereby $76 \%$ of preterm and $28 \%$ of term infants had morbidities ${ }^{11}$. The most common morbidities among preterm infants were RDS (75.2\%) and apnea (72.3\%). Similarly, previous studies have reported respiratory complications, including RDS and apnea, as the most common complications among preterm infants ${ }^{19,20}$. For term infants, the most common condition was jaundice (53.9\%). Respiratory complications affected only around one-third of the term infants, making them at five times less risk compared to preterm infants. Likewise, six times increased risk of respiratory complications among preterm infants was reported in a previous study determining the role of gestational age on neonatal morbidity ${ }^{19}$. Unlike term infants, preterm infants are at higher risk of RDS and apnea because they are more likely not to have made a sufficient amount of surfactant in their lungs at the time of birth and are likely to have an immature nervous system 21,22 .

Among the leading causes of death in children are infections such as sepsis and pneumonia ${ }^{4}$. In subSaharan Africa, for instance, pneumonia is the leading cause of mortality in under-five children ${ }^{3}$. In the present study, compared to term infants, preterm infants had a higher risk of both sepsis (51.0\% vs. $19.0 \%)$ and pneumonia (25.2\% vs. $11.1 \%)$. It was found that the odds of sepsis and pneumonia were two and three folds higher $(\mathrm{OR}=2.6,95 \% \mathrm{Cl} ; 1.7-3.9$ and $\mathrm{OR}=2.7,95 \% \mathrm{Cl} ; 1.6-4.6)$, respectively, in preterm infants. A two-fold increased risk of neonatal infection among preterm infants has also been reported in other studies investigating adverse neonatal outcomes and the epidemiology of neonatal sepsis ${ }^{23,24}$. Immunological deficiencies among preterm infants make them fail to fight early life infections cause of the higher risk of infections ${ }^{25}$.

About $51.5 \%$ of preterm infants and $19.8 \%$ of term infants had anemia resulting in four times increased risk in preterm infants $(\mathrm{OR}=4.3,95 \% \mathrm{Cl} ; 2.8-6.6)$. The incidence of $58.2 \%$ and $21.0 \%$ for preterm and term infants, respectively, were also reported elsewhere 26,27 . Compared to term infants, typically preterm 
infants have a lower number of red blood cells which also have a short life span, thus exposing them to an increased risk of anemia that may require blood transfusion ${ }^{28}$. NEC, on the other hand, was not as common as other complications. However, the risk was five times higher for preterm infants. Likewise, four times increased risk among preterm infants was observed in a retrospective study conducted in late preterm infants, although only $0.4 \%$ of preterm and $0.1 \%$ term infants had NEC ${ }^{29}$. Despite the low prevalence reported in different studies, NEC is among the most detrimental neonatal outcomes. It is associated with a high mortality rate among victims, particularly preterm infants and it is the leading cause of death among infants admitted in NICUs ${ }^{30}$.

The overall odds of morbidity were seven times higher among preterm infants compared to term infants. Similar odds of morbidity among preterm infants were reported in a study conducted in Switzerland ${ }^{18}$. The proportion of infants with adverse outcomes increased with decreased gestational age. Various studies have documented that the longer the baby stays in the womb, the lower the risk of adverse neonatal outcomes ${ }^{13,29,31}$. Since the assessment of adverse neonatal outcomes in this study was done between birth and discharge, cases of the outcomes following discharge were unidentified. However, with an adequate number of enrolled participants, we could still establish significant findings that align with similar studies from different parts of the world.

\section{Conclusion}

The most common adverse neonatal outcomes among preterm are different from those of term infants. Preterm infants have an increased risk of mortality, apnea, RDS, NEC, anemia, pneumonia and sepsis in the first month of life compared to term infants. No increased risk was observed for IVH, BPD, PDA and jaundice. With further research, the findings of this study may inform the Tanzanian health sector about the most common and high risk neonatal outcomes in preterm infants. Through this information, existing guidelines can be refined. Also, new guidelines can be established that will incorporate strategies for promoting infants' health through preventing and treating the most common and high risk adverse neonatal outcomes in preterm infants.

\section{List Of Abbreviations}




\begin{tabular}{|ll|}
\hline BPD & Bronchopulmonary dysplasia \\
\hline $\mathrm{Cl}$ & Confidence interval \\
\hline IVH & Intraventricular hemorrhage \\
\hline NEC & Necrotizing enterocolitis \\
\hline MNH & Muhimbili National Hospital \\
\hline NICU & Neonatal Intensive Care Unit \\
\hline OR & Odds ratio \\
\hline PDA & Patent ductus arteriosus \\
\hline RDS & Respiratory distress syndrome \\
\hline WHO & World Health Organization \\
\hline
\end{tabular}

\section{Declarations}

\section{Ethics approval and consent to participate}

Neonates were included in the study after obtaining informed consent from their parents. The National Health Research Ethics Committee (NatHREC) of the National Institute of Medical Research (NIMR) approved this study with reference number NIMR/HD/R.8a/Vol.IX/3006.

\section{Consent for publication}

Not applicable.

\section{Availability of data and materials}

All data presented in the manuscript can be obtained upon request to the corresponding author.

\section{Competing interests}

The authors declare that they have no competing interests.

\section{Funding}

This work was funded by the Swedish International Development Cooperation Agency (SIDA) and the University of Dar es Salaam (UDSM) bilateral programme under PhD in Molecular Biosciences programme.

\section{Authors' contributions}


BTR conducted literature searches, analyzed and interpreted data, and had a primary responsibility of writing the manuscript. RZS, EBR, SLY and SNM analyzed data, reviewed and revised the manuscript, and contributed significantly to editing the manuscript. All authors read and approved the final manuscript.

\section{Acknowledgements}

We acknowledge the SIDA-UDSM bilateral programme under PhD in Molecular Biosciences programme for funding this study. We also thank Dr. Lukumay, Mrs Kileo and all the staff at the MNH maternity and neonatal wards who helped recruit the study participants.

\section{References}

1. Pitchon RR, Alvim CG, Andrade CR de, et al. Asthma mortality in children and adolescents of Brazil over a 20-year period. J Pediatr (Rio J). 2020;96(4):432-438. doi:10.1016/j.jped.2019.02.006

2. Cao H, Wang J, Li Y, et al. Trend analysis of mortality rates and causes of death in children under 5 years old in Beijing, China from 1992 to 2015 and forecast of mortality into the future: An entire population-based epidemiological study. BMJ Open. 2017;7(9):1-11. doi:10.1136/bmjopen-2017015941

3. Liu L, Oza S, Hogan D, et al. Global, regional, and national causes of under-5 mortality in 2000-15: An updated systematic analysis with implications for the Sustainable Development Goals. Lancet. 2016;388(10063):3027-3035. doi:10.1016/S0140-6736(16)31593-8

4. Lawn E, Cousens S, Zupan J. 4 million neonatal deaths: When? Where? Why? Lancet. 2005;365:891900. doi:10.1016/S0140-6736(05)71048-5

5. WHO. Maternal and child epidemiology estimation group. Child causes of death 2000-2017. Published online March 1, 2018. doi:10.1093/jac/49.3.497

6. Plan SO. The national road map strategic plan to accelerate reduction of maternal, newborn and child deaths in Tanzania (2008-15). Published online 2014:1-76. https://www.who.int/pmnch/countries/tanzaniamapstrategic.pdf

7. Mmbaga BT, Lie RT, Olomi R, et al. Cause-specific neonatal mortality in a neonatal care unit in Northern Tanzania: a registry based cohort study. BMC Pediatr. 2012;12(116). doi:10.1186/14712431-12-116

8. Mangu CD, Rumisha SF, Lyimo EP, et al. Trends, patterns and cause-specific neonatal mortality in Tanzania: a hospital-based retrospective survey. Int Health. 2020;0:1-10. doi:10.1093/inthealth/ihaa070

9. Sania A, Smith ER, Manji K, et al. Neonatal and infant mortality risk associated with preterm and small for gestational age births in Tanzania: Individual level pooled analysis using the intergrowth standard. J Pediatr. 2018;192:66-72. doi:10.1016/j.jpeds.2017.09.007

10. Manji K. Situation analysis of newborn health in Tanzania: Current situation, existing plans and strategic next steps for newborn health. Minist Heal Soc Welf. Published online 2009. 
https://www.countdown2015mnch.org/wp-

content/uploads/2013/02/Tanzania_SituationAnalysis_Newborn.pdf

11. Amin T, Nur AN. Morbidity and mortality outcome in late preterm neonates at a tertiary care hospital. J Armed Forces Med Coll Bangladesh. 2016;12(1):44-47. doi:10.3329/jafmc.v12i1.39966

12. Schindler T, Koller-Smith L, Lui K, et al. Causes of death in very preterm infants cared for in neonatal intensive care units: A population-based retrospective cohort study. BMC Pediatr. 2017;17(1):1-9. doi:10.1186/s12887-017-0810-3

13. Manuck TA, Rice MM, Bailit JL, et al. Preterm neonatal morbidity and mortality by gestational age: A contemporary cohort. Am J Obstet Gynecol. 2016;215(1):103.e

1-103.e14

. doi:10.1016/j.ajog.2016.01.004

14. Ashish K, Wrammert J, Nelin V, et al. Level of mortality risk for babies born preterm or with a small weight for gestation in a tertiary hospital of Nepal. BMC Public Health. 2015;15(1):1-9. doi:10.1186/s12889-015-2232-1

15. Yasmin S, Osrin D, Paul E, Costello A. Neonatal mortality of low-birth-weight infants in Bangladesh. Bull World Health Organ. 2001;79(7):608-614. doi:10.1590/S0042-96862001000700005

16. Costeloe KL, Hennessy EM, Haider S, et al. Short term outcomes after extreme preterm birth in England: Comparison of two birth cohorts in 1995 and 2006 (the EPICure studies). BMJ. 2012;345(7886):1-14. doi:10.1136/bmj.e7976

17. Muhe LM, McClure EM, Mekasha A, et al. A prospective study of causes of illness and death in preterm infants in Ethiopia: The SIP study protocol. Reprod Health. 2018;15(1):1-9. doi:10.1186/s12978-018-0555-y

18. Leone A, Ersfeld $P$, Adams $M$, et al. Neonatal morbidity in singleton late preterm infants compared with full-term infants. Acta Paediatr Int J Paediatr. 2012;101(1):6-10. doi:10.1111/j.16512227.2011.02459.x

19. Brown HK, Speechley KN, Macnab J, et al. Neonatal morbidity associated with late preterm and early term birth: The roles of gestational age and biological determinants of preterm birth. Int J Epidemiol. 2014;43(3):802-814. doi:10.1093/ije/dyt251

20. Walsh MC, Bell EF, Kandefer S, et al. Neonatal outcomes of moderately preterm infants compared to extremely preterm infants. Pediatr Res. 2017;82(2):297-304. doi:10.1038/pr.2017.46

21. Ginsburg D, Maken K, Deming D, et al. Etiologies of apnea of infancy. Pediatr Pulmonol. 2020;55(6):1495-1502. doi:10.1002/ppul.24770

22. Amigoni A, Pettenazzo A, Stritoni V, Circelli M. Surfactants in Acute Respiratory Distress Syndrome in Infants and Children: Past, Present and Future. Clin Drug Investig. 2017;37(8):1-8. doi:10.1007/s40261-017-0532-1

23. Braye K, Foureur M, De Waal K, et al. Epidemiology of neonatal early-onset sepsis in a geographically diverse Australian health district 2006-2016. PLoS One. 2019;14(4):1-14.

doi:10.1371/journal.pone.0214298 
24. Sengupta S, Carrion V, Shelton J, et al. Adverse neonatal outcomes associated with early-term birth. JAMA Pediatr. 2013;167(11):1053-1059. doi:10.1001/jamapediatrics.2013.2581

25. Sharma AA, Jen R, Butler A, Lavoie PM. The developing human preterm neonatal immune system: $A$ case for more research in this area. Clin Immunol. 2012;145(1):61-68. doi:10.1016/j.clim.2012.08.006

26. Banerjee J, Asamoah FK, Singhvi D, et al. Haemoglobin level at birth is associated with short term outcomes and mortality in preterm infants. BMC Med. 2015;13(1):1-7. doi:10.1186/s12916-0140247-6

27. Lee S, Guillet R, Cooper EM, et al. Prevalence of anemia and associations between neonatal iron status, hepcidin, and maternal iron status among neonates born to pregnant adolescents. Pediatr Res. 2016;79(1):42-48. doi:10.1038/pr.2015.183

28. Strauss R. Anaemia of prematurity: Pathophysiology \& treatment. Growth (Lakeland). 2008;23(1):17. doi:10.1038/jid.2014.371

29. Melamed N, Klinger G, Tenenbaum-Gavish K, et al. Short-term neonatal outcome in low-risk, spontaneous, singleton, late preterm deliveries. Obstet Anesth Dig. 2010;30(3):152.

doi:10.1097/01.aoa.0000386821.22935.b9

30. Neu J. Neonatal necrotizing enterocolitis: An update. Acta Paediatr. 2005;94(449):100-105. doi:10.1111/j.1651-2227.2005.tb02163.x

31. Tsai ML, Lien R, Chiang MC, et al. Prevalence and morbidity of late preterm infants: Current status in a medical center of Northern Taiwan. Pediatr Neonatol. 2012;53(3):171-177.

doi:10.1016/j.pedneo.2012.04.003

\section{Figures}




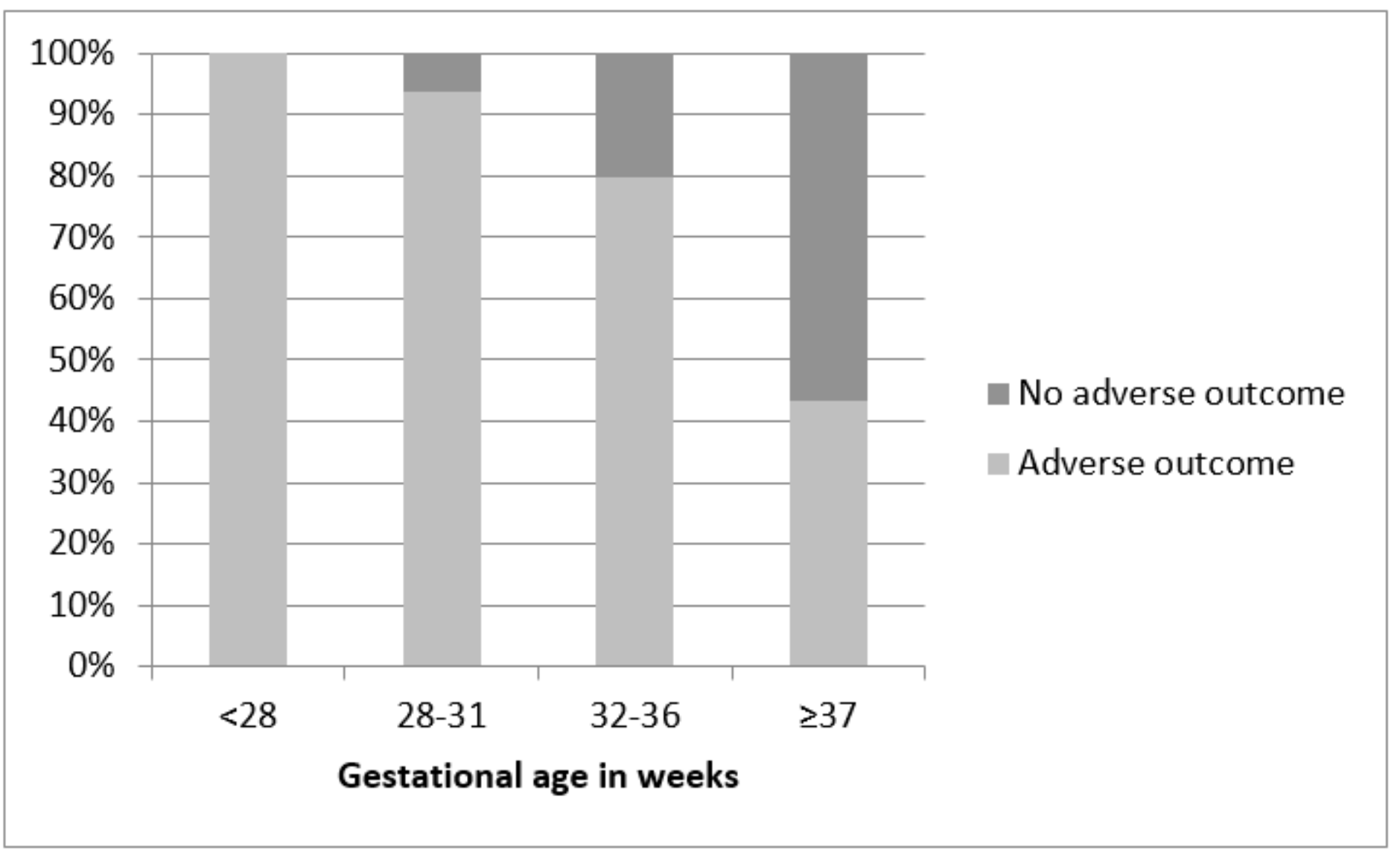

\section{Figure 1}

Proportion of infants with and without health complications across gestational age groups 


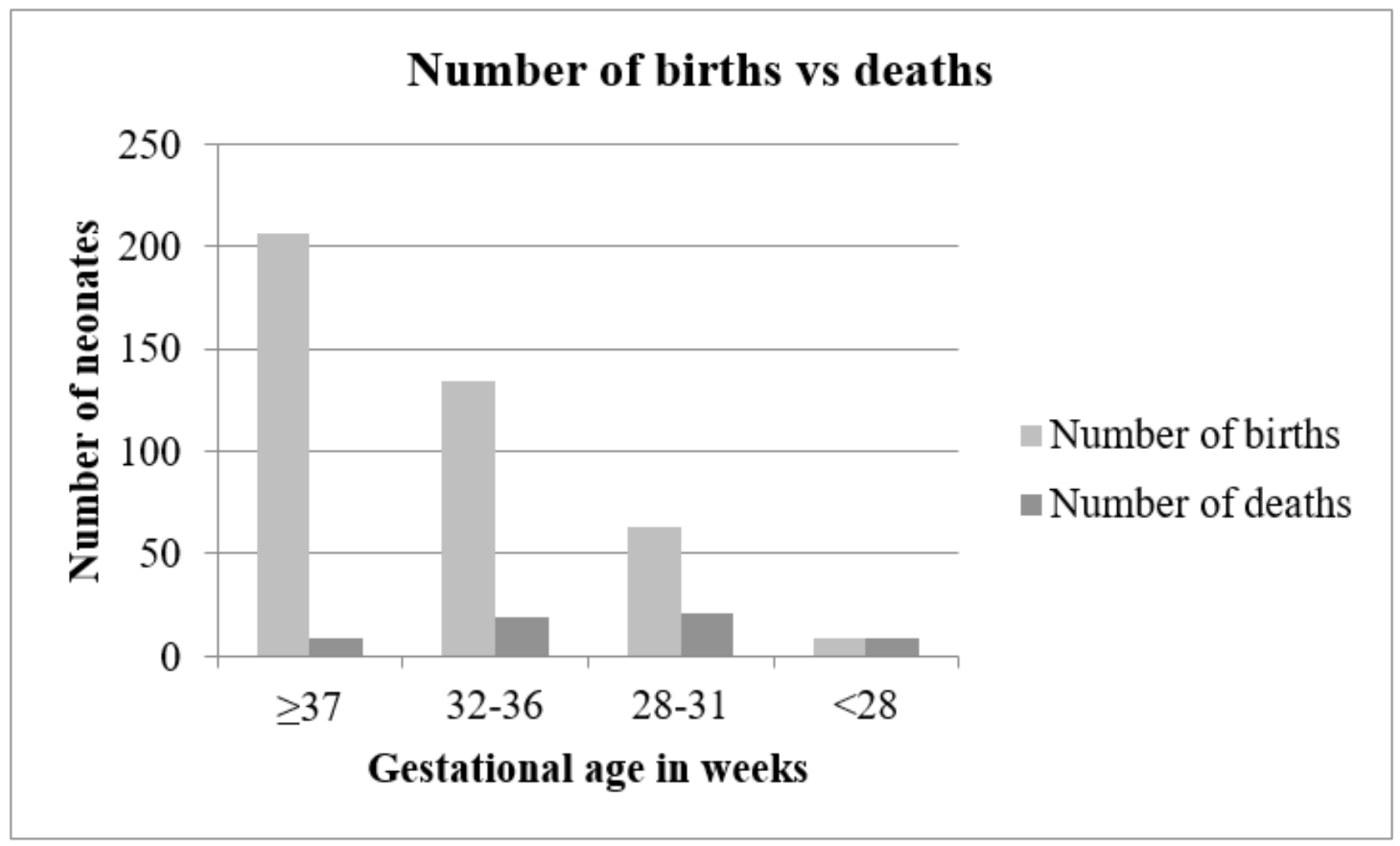

Figure 2

Number of births versus number of deaths at different gestational ages groups 